И.В. Башлаков-Николаев, Российский экономический университет им. Г.В. Плеханова, Ассоциация антимонопольных экспертов, г. Москва

\section{Аннотация}

На примере судостроительной отрасли в статье рассматриваются проблемы нормативного правового закрепления целей (ожидаемых результатов) развития конкуренции в Национальном плане развития конкуренции в Российской Федерации на 2018-2020 гг. и Дорожной карте Правительства по развитию конкуренции в отдельных отраслях экономики. Такими целями на сегодня признаны создание конкурентоспособной продукции и развитие экспорта данной продукции. Нормативно закрепленные цели развития конкуренции в промышленности не являются для государства непреодолимым препятствием для предоставления отдельным российским производителям (в частности, судостроителям) неконкурентных преимуществ (преференций) для достижения тех или иных социально значимых целей. При этом антимонопольное законодательство страны не регламентирует процедуры и механизм компенсации убытков, возникающих в результате легального ограничения конкуренции в случаях, не подпадающих под установленные им антимонопольные запреты. Это несет в себе потенциальную угрозу снижения качества инвестиционного климата и деловой активности (в том числе в сфере судостроения).

Ключевые слова: конкуренция, конкурентоспособность, развитие, цели, ожидаемые результаты, промышленная политика, промышленность, судостроение, преференции.

\title{
Regulatory objectives (expected results) the development of competition in the industry (on the example of shipbuilding)
}

\section{V. Bashlakov-Nikolaev, \\ Russian University of Economics n.a. G. V. Plekhanov, Association of antimonopoly experts, Moscow}

\section{Annotation}

On the example of the shipbuilding industry, the article deals with the problems of regulatory legal consolidation of the objectives (expected results) of competition development in the National plan of competition development in the Russian Federation for 2018-2020 and the Road map of the Government for the development of competition in certain sectors of the economy. Such goals are recognized today: the creation of competitive products and the development of exports of these products. Regulate the development of competition in the industry are not for the state an insurmountable obstacle to the provision of certain Russian manufacturers (particularly shipbuilders) uncompetitive advantages (preferences) for achieving certain socially significant goals. At the same time, the antimonopoly legislation of the country does not regulate the procedures and mechanism for compensation of losses arising as a result of legal restriction of competition in cases not covered by the antimonopoly prohibitions established by it. This carries a potential threat of reducing the quality of the investment climate and business activity (including shipbuilding). 
Нормативные цели (ожидаемые результаты) развития конкуренции в сфере промышленности...

2018 г. Минпромторгом России был разработан законопроект ${ }^{1}$ о внесении изменений в Кодекс торгового мореплавания Российской Федерации², которые направлены на введение запрета на использование на Северном морском пути (далее - СМП) с 2019 г. новых судов, построенных за рубежом.

Запретительный режим направлен на стимулирование российского судостроения через формирование гарантированного спроса. При создании запрета не учитывается то, что в настоящее время российское судостроение не обладает потенциалом, способным обеспечить своевременное выполнение заказов на производство ледоколов и судов ледового класса, предназначенных для перевозки грузов по СМП.

Указанный фактор создает угрозу недостижения показателей развития объемов перевозок по СМП в 80 млн тонн и выполнения российскими грузоотправителями контрактных обязательств перед иностранными покупателями товаров, доставляемых через СМП.

Среди возможных причин срыва сроков строительства судов называются недостаточность экономических, финансовых и технологических ресурсов у российских судостроительных компаний, а также то, что в настоящее время российская судостроительная отрасль (за некоторыми исключениями) не в состоянии эффективно конкурировать с иностранными судостроительными организациями.

Сложившаяся в отечественном судостроении ситуация ставит ряд вопросов, связанных с защитой и развитием конкуренции в этой отрасли промышленности, обусловленных принятием управленческих решений о постройке судов, необходимых для обеспечения перевозки грузов по Северному морскому пути, конкретной российской верфью. Данные решения, на наш взгляд, с одной стороны предоставляют преимущество конкретным хозяйствующим субъектам, а с другой — ограничивают конкуренцию.

Рассмотрим указанные проблемы сквозь призму буквы и духа документов стратегического планирования в сфере конкуренции.

\section{Цели (ожидаемые результаты) развития конкуренции в Национальном плане развития конкуренции в Российской Федерации на 2018-2020 гг.}

Указом Президента Российской Федерации от 21.12.2018 №618 (далее - Указ №618) утвержден Национальный план развития конкуренции в Российской Федерации на 2018-2020 гг. (далее - Национальный план разви-

1 CM.: https://www.kommersant.ru/doc/3675554?from=doc_vrez по состоянию на 12.07.2018.

2 См.: Кодекс торгового мореплавания Российской Федерации от 30.04.1999 № 81-Ф3 (ред. от 27.12.2018) (с изм. и доп., вступ. в силу с 31.01.2019) // СЗ РФ. 03.05.1999. № 18. Ст. 2207. тия конкуренции), общие цели (т. е. ожидаемые результаты) [1, 2] $]^{3}$ развития конкуренции не определены.

Вместе с тем в П. 2 Указа названы цели совершенствования государственной политики по развитию конкуренции в целом. К их числу отнесены: а) рост удовлетворенности потребителей за счет расширения ассортимента товаров, повышения их качества и снижения цен; б) рост экономической эффективности и конкурентоспособности хозяйствующих субъектов, в том числе за счет обеспечения равного доступа к товарам и услугам субъектов естественных монополий и государственным услугам, необходимым для ведения предпринимательской деятельности, стимулирования инновационной активности хозяйствующих субъектов, повышения доли наукоемких товаров и услуг в структуре производства, развития рынков высокотехнологичной продукции; в) стабильный рост и развитие многоукладной экономики, технологий, снижение издержек в экономике в целом, социальной напряженности в обществе, обеспечение национальной безопасности".

Достижение указанных выше ожидаемых результатов экономического, общесоциального и политического характера, по-видимому, следует рассматривать в качестве бессрочных (постоянных) челей совершенствования государственной политики России по развитию конкуренции.

Совокупность отраслевых челей развития конкуренции на трехлетний период определена в качестве ожидаемых результатов в Перечне отраслей (сфер) экономики (видов деятельности) и ожидаемых результатов развития конкуренции, размещенном в качестве приложения к Национальному плану развития конкуренции.

В п. 12 данного Перечня закреплены следующие цели (ожидаемые результаты) развития конкуренции в сфере промышленности:

- «создание условий для производства российских товаров, способных эффективно конкурировать с зарубежными аналогами на внутреннем и внешнем рынках;

- увеличение доли экспорта российских промышленных товаров в общем объеме промышленных товаров, произведенных на территории Российской Федерации» ${ }^{5}$.

Анализ п. 12 Перечня показывает, что конкуренция в промышленной сфере рассматривается в качестве од-

3 Господствующим в современной философии значением понятия цели является «предвосхищение в мышлении результата деятельности и пути его реализации с помощью определенных средств». См. также: Taylor R. Action and purpose. N.Y.: Humanities Press, 1973. $269 p$

4 См.: Указ Президента РФ от 21.12.2017 № 618 «Об основных направлениях государственной политики по развитию конкуренции» (вместе с «Национальным планом развития конкуренции в Российской Федерации на 2018-2020 гг.») // СЗ РФ. 25.12.2017. №52 (часть І). Ст. 8111.

5 СЗ РФ. 25.12.2017. № 52 (часть I). Ст. 8111. 
ного из средств обеспечения конкурентоспособности российских товаров и увеличения доли экспорта. При этом приоритет конкуренции перед иными средствами обеспечения конкурентоспособности в указанном выше документе не определен. Таким образом, из анализа рассматриваемого документа следует, что целью развития конкуренции в сфере промышленности, понимаемой в качестве совокупности отраслей промышленности [3], является обеспечение конкурентоспособности отечественной промышленной продукцич ${ }^{6}$.

При этом нужно учитывать, что Национальный план развития конкуренции не содержит отраслевой структуры промышленности. Такая дифференциация (относительно полная) была дана позже в приложении к Распоряжению Правительства РФ от 16.08.2018 № 1697-р, которым был утвержден план мероприятий (дорожная карта) по развитию конкуренции в отраслях экономики РФ и переходу отдельных сфер естественных монополий из состояния естественной монополии в состояние конкурентного рынка на 2018-2020 гг. (далее - Дорожная карта Правительства по развитию конкуренции в отдельных отраслях экономики) ${ }^{7}$.

\section{Цели (ожидаемые результаты) развития конкуренции в сфере промышленности, предусмотренные Дорожной картой Правительства по развитию конкуренции в отдельных отраслях экономики}

Подпунктами 22 и 23 п. 4 раздела I Дорожной карты Правительства по развитию конкуренции в отдельных отраслях экономики предусмотрены те же цели (ожидаемые результаты) развития конкуренции в сфере промышленности, что и в рассмотренном п. 12 Перечня отраслей (сфер) экономики (видов деятельности) и ожидаемых результатов развития конкуренции, размещенного в качестве приложения к Национальному плану развития

6 В связи с этим нельзя не отметить, что режимы ограничения использования в мореплавании на СМП судов, плавающих не под российским флагом, и использования судов нероссийского производства преследуют те же цели, что и конкуренция - обеспечение конкурентоспособности продукции, услуг и работ российского происхождения. - Прим. авт.

7 См: Основные виды деятельности в отраслях экономики, в которых необходимо достижение контрольных показателей реализации плана мероприятий («дорожной карты») по развитию конкуренции в отраслях экономики Российской Федерации и переходу отдельных сфер естественных монополий из состояния естественной монополии в состояние конкурентного рынка на 2018-2020 гг. // Распоряжение Правительства РФ от 16.08.2018 № 1697-р (ред. от 20.11.2018) «Об утверждении плана мероприятий («дорожной карты») по развитию конкуренции в отраслях экономики Российской Федерации и переходу отдельных сфер естественных монополий из состояния естественной монополии в состояние конкурентного рынка на 2018-2020 гг. // СЗ РФ. 03.09.2018. №36. Ст. 5655. конкуренции. В качестве органов государственной власти, ответственных за достижение этих целей (ожидаемых результатов), указаны Минпромторг России и ФАС России ${ }^{8}$.

Необходимо отметить, что в соответствии с Федеральным законом от 31.12.2014 № 488-Ф3 «0 промышленной политике в Российской Федерации» (далее - Закон о промышленной политике) одной из задач промышленной политики является вполне соотносимое с предусмотренными в Национальном плане развития конкуренции и Дорожной карте Правительства по развитию конкуренции увеличение выпуска продукции с высокой долей добавленной стоимости и поддержка экспорта такой продукции (п. 5 ч. 4 ст. 4)9. Задачи промышленной политики, определенные в ч. 2 ст. 4 указанного Закона, сформулированы законодателем намного шире, чем цели развития конкуренции в сфере промышленности в соответствии с Дорожной картой Правительства по развитию конкуренции в отдельных отраслях экономики.

Таким образом, развитие конкуренции направлено на решение одной из задач промышленной политики.

Подразделом XIII «Промышленность» раздела II «План развития конкуренции» Дорожной карты Правительства по развитию конкуренции в отдельных отраслях экономики предусмотрены следующие мероприятия:

1) обеспечение присутствия в отраслях промышленности (за исключением сфер деятельности субъектов естественных монополий и организаций оборонно-промышленного комплекса) не менее трех хозяйствующих субъектов, из которых по меньшей мере один относится к частному бизнесу ${ }^{10}$;

2) внесение изменений в документы, утверждающие стратегии развития отраслей промышленности, планы развития отраслей промышленности, включение во вновь разрабатываемые отраслевые документы стратегического планирования мероприятий, направленных на развитие конкуренции в отраслях промышленности, предусматривающих:

а) оценку текущего состояния отрасли в РФ в целях разработки мер, влияющих на развитие конкуренции, включая оценку количества присутствующих в определенной отрасли промышленности хозяйствующих субъектов и доли частного сектора;

8 Для рынка грузовых перевозок водным транспортом в качестве цели, т. е. ожидаемого к 2020 г. результата (пп. 26 п. 4 раздела I), названо развитие добросовестной конкуренции на соответствующем рынке, что, на наш взгляд, может быть объяснено лишь недостатком времени для серьезной экспертной проработки проблемы целеполагания развития конкуренции на указанном рынке. - Прим. авт.

9 См.: СЗ РФ. 05.01.2015. № 1 (часть I). СТ. 41.

10 Речь в данном случае идет именно об отраслях промышленности (!), а не о товарных рынках, применительно к которым обычно анализируется и оценивается состояние конкуренции. Прим. авт. 
Нормативные цели (ожидаемые результаты) развития конкуренции в сфере промышленности...

б) определение мероприятий, направленных на развитие конкуренции и присутствие на рынке не менее трех хозяйствующих субъектов, а также повышение конкурентоспособности отраслей на внутреннем и внешнем рынках;

3) внесение изменений в нормативные 11 акты РФ, предусматривающие снижение административных барьеров в сфере сертификации в отраслях промышленности;

4) внесение изменений в акты, регламентирующие ведение официального статистического учета и функционирование системы государственной статистики в РФ (в том числе в Федеральный план статистических работ) ${ }^{12}$, в части распространения субъектами официального статистического учета официальной статистической информации с разбивкой данных по частному и государственному сектору на федеральном уровне и уровне субъекта РФ, а также представления Росстатом агрегированных и деперсонифицированных статистических данных по запросу федеральных органов исполнительной власти с обязательным соблюдением принципа конфиденциальности первичных статистических данных;

5) развитие конкуренции при осуществлении процедур государственных и муниципальных закупок, а также закупок хозяйствующих субъектов, в том числе за счет расширения участия в указанных процедурах субъектов малого и среднего предпринимательства;

6) внесение изменений в документы, утверждающие стратегии развития отраслей промышленности, планы развития отраслей промышленности, включение во вновь разрабатываемые отраслевые документы стратегического планирования мероприятий, направленных на развитие конкуренции в отраслях промышленности, предусматривающих: а) оценку текущей доли закупок у субъектов малого и среднего предпринимательства; б) определение мероприятий, направленных на обеспечение конкуренции при государственных и муниципальных закупках, с определением в них перечней ключевых показателей, обеспечивающих в том числе достижение ожидаемых результатов в отраслях (сферах) промышленности;

7) обеспечение создания условий в отраслях промышленности для производства российских товаров, способных эффективно конкурировать с зарубежными аналогами на внутреннем и внешнем рынках;

11 Данное положение касается нормативных, а не только нормативных правовых актов, что преодолеет внесение изменений, например, в национальные стандарты, не приобретшие силу нормативных правовых актов, различного рода рекомендации, письма нормативного характера, не являющиеся нормативными правовыми актами. - Прим. авт.

12 См.: Распоряжение Правительства РФ от 06.05.2008 № 671-р (ред. от 10.04.2019) «Об утверждении Федерального плана статистических работ» (вместе с «Федеральным планом статистических работ») // СЗ РФ. 19.05. 2008. №20. Ст. 2383.
8) внесение изменений в документы, утверждающие стратегии развития отраслей промышленности, планы развития отраслей промышленности, включение во вновь разрабатываемые отраслевые документы стратегического планирования мероприятий, направленных на развитие конкуренции в отраслях промышленности, предусматривающих: а) оценку текущей доли экспорта российских товаров отраслей промышленности; б) оценку уровня конкурентоспособности российских товаров отраслей промышленности по отношению к зарубежным товарам-аналогам на внутреннем и внешнем рынках; в) определение мероприятий, направленных на обеспечение производства российской продукции, способной конкурировать с иностранной;

9) внесение изменений в нормативные правовые акты РФ в части разработки и утверждения Методики оценки конкурентоспособности товаров отраслей промышленности по отношению к зарубежным товарам-аналогам на внутреннем и внешнем рынках;

10) осуществление мониторинга и оценки действий иностранных поставщиков (производителей), оказывающих влияние на условия конкуренции на территории РФ;

11) создание единой информационно-справочной системы в целях развития конкуренции в соответствующих отраслях промышленности Российской Федерации на базе государственной информационной системы промышленности, предусматривающей: а) обеспечение комплексного представления информации об отрасли; б) расширение методов сбора информации о хозяйствующих субъектах всех организационно-правовых форм собственности, действующих на товарных рынках отрасли; в) определение порядка получения и передачи в органы, на которые будет возложена реализация последующих планов развития конкуренции (дорожных карт), информации о деятельности на товарных рынках хозяйствующих субъектов; г) интеграцию информационных ресурсов Минпромторга России, других федеральных органов исполнительной власти и органов исполнительной власти субъектов РФ; д) обеспечение использования существующих и создание новых баз и банков данных для анализа количественных и качественных показателей товарных рынков соответствующих отраслей; е) информирование о реализации мероприятий, предусмотренных п. 1 и 5 подразд. XIII разд. II «План развития конкуренции» Дорожной карты Правительства по развитию конкуренции в отдельных отраслях экономики, а также их показателях (увеличение доли закупок у субъектов малого и среднего предпринимательства, увеличение доли экспорта, увеличение доли частного сектора, снижение доли государственного сектора в экономике);

12) установление ограничений на предоставление мер государственной и (или) муниципальной поддержки хозяйствующим субъектам в сфере промышленности, направленных на расширение производственных мощностей (в том числе путем создания дополнительных 
производственных мощностей) для производства продукции, рынки которой характеризуются профицитными мощностями и наличием более двух производителей на территории РФ (за исключением создания новых производственных мощностей, сопровождающегося соразмерным прекращением функционирования существующих мощностей);

13) внесение изменений в Федеральный закон «О промышленной политике в Российской Федерации», иные акты в целях совершенствования механизма использования специальных инвестиционных контрактов;

14) внесение изменений в Федеральный закон «О техническом регулировании» ${ }^{13}$, иные акты в части разработки и утверждения Методики определения размера платы за оказание необходимых и обязательных работ по подтверждению соответствия продукции, объектов, процессов, работ, услуг требованиям технических регламентов, проводимых в соответствии с законодательством РФ о техническом регулировании;

15) внесение изменений в Федеральный закон «О промышленной политике в Российской Федерации» в части разработки и утверждения Методики оценки эффективности предоставления субсидий на развитие отраслей промышленности;

16) принятие ведомственного акта в части предупреждения, выявления и пресечения нарушений федеральным органом исполнительной власти требований федеральных законов «О защите конкуренции», «0 государственном оборонном заказе», «О контрактной системе в сфере закупок товаров, работ, услуг для обеспечения государственных и муниципальных нужд» и «О закупках товаров, работ, услуг отдельными видами юридических лиц»;

17) создание конкурентных условий допуска кредитных организаций к привлечению денежных средств на банковские депозиты (счета) и другие инструменты денежного рынка, порядка размещения таких денежных средств на банковских депозитах (счетах) и других инструментах денежного рынка, допуска кредитных организаций к выдаче банковских гарантий для обеспечения исполнения обязательств третьих лиц, а также предоставления кредиторам субсидий из федерального бюджета при предоставлении льготного финансирования.

Из числа указанных выше мероприятий к мероприятиям по развитию конкуренции, на наш взгляд, можно отнести лишь мероприятия, предусмотренные пп. 1, 2, 3, 5, 6, 11, 12, 16, 17. Мероприятия, предусмотренные пп. 7-9, имеют отношение к обеспечению конкурентоспособности российских товаров, а мероприятие, предусмотренное п. 10, - к развитию конкуренции и обеспечению конкурентоспособности. Мероприятия, указанные

13 См.: Федеральный закон от 27.12.2002 №184-Ф3 «0 техническом регулировании» // СЗ РФ. 30.12.2002. №52 (часть І). Ст. 5140. в приведенных пп. 13-15, по нашему мнению, связаны с решением задач совершенствования механизмов поддержки промышленности, из описания которых невозможно установить, будут ли они направлены на развитие конкуренции или на ее ограничение.

Необходимо отметить, что конкретные отраслевые мероприятия по развитию конкуренции должны определяться федеральными органами исполнительной власти в рамках реализации положений подразд. XIII разд. II «План развития конкуренции» Дорожной карты Правительства по развитию конкуренции в отдельных отраслях экономики.

\section{Цели развития конкуренции в сфере промышленности}

Анализ Национального плана развития конкуренции и Дорожной карты Правительства по развитию конкуренции в отдельных отраслях экономики позволяет выделить следующие цели (ожидаемые результаты) развития конкуренции в сфере промышленности: 1) повышение удовлетворенности потребителей за счет расширения ассортимента товаров, работ, услуг, повышения их качества и снижения цен; 2) повышение экономической эффективности и конкурентоспособности хозяйствующих субъектов, в том числе за счет обеспечения равного доступа к товарам и услугам субъектов естественных монополий и государственным услугам, необходимым для ведения предпринимательской деятельности, стимулирования инновационной активности хозяйствующих субъектов, повышения доли наукоемких товаров и услуг в структуре производства, развития рынков высокотехнологичной продукции; 3) стабильный рост и развитие многоукладной экономики, развитие технологий, снижение издержек в масштабе национальной экономики, снижение социальной напряженности в обществе, обеспечение национальной безопасности.

Целями промышленной политики, установленными 4. 1 ст. 4 Закона о промышленной политике, являются: 1) формирование высокотехнологичной, конкурентоспособной промышленности, обеспечивающей переход экономики государства от экспортно-сырьевого типа развития к инновационному типу развития; 2) обеспечение обороны страны и безопасности государства; 3) обеспечение занятости населения и повышение уровня жизни граждан Российской Федерации.

Очевидно, что цели промышленной политики являются более общими по сравнению с целями развития конкуренции в сфере промышленности. Означает ли это, что цели развития конкуренции в сфере промышленности могут противоречить целям промышленной политики? Нет, не означает. Например, по смыслу п. 4 Указа №618 запрещается вводить и (или) сохранять ограничения, создающие дискриминационные условия в отношении отдельных видов экономической деятельности, про- 
Нормативные цели (ожидаемые результаты) развития конкуренции в сфере промышленности...

изводства и оборота отдельных видов товаров (услуг), за исключением случаев, предусмотренных федеральными законами, правовыми актами Президента и Правительства РФ.

Таким образом, если для достижения целей промышленной политики государство в лице федерального законодателя, главы государства и Правительства страны сочтет необходимым отступить от достижения намеченных целей развития конкуренции и ограничить развитие конкуренции в отдельных секторах, отраслях промышленности, исходя из целей промышленной политики (например, обеспечение безопасности государства), то оно всегда сможет это сделать на законных основаниях. Однако при этом остается неурегулированным вопрос о компенсации убытков, возникающих в результате ограничения общих правил конкуренции, ее защиты и развития.

На наш взгляд, одним из важнейших условий преодоления возможных противоречий между целями промышленной политики (в том числе относящимися к судостроению) является соответствие средств развития конкуренции в промышленной сфере целям промышленной политики, т.е. государственного управления в сфере промышленности. Таким образом, регламентация целеполагания по развитию конкуренции в промышленной сфере должна быть дополнена детальной регламентацией средств и методов достижения этих целей, условий и пределов использования таких средств и способов. $\mathrm{K}$ сожалению, эту работу еще только предстоит выполнить, предварительно ответив на общие вопросы. K числу таких вопросов, в частности, относится законодательная регламентация системы, принципов, методов и средств развития конкуренции, которая может быть реализована, например, в перспективном Кодексе Российской Федерации о конкуренции [4].

\section{Выводы}

1. Нормативно закрепленными целями (ожидаемыми результатами) развития конкуренции в сфере промышленности (в том числе в судостроительной) в нашей стране на сегодня признаны создание конкурентоспособной продукции и развитие экспорта данной продукции.

2. Нормативно закрепленные цели развития конкуренции в промышленности не являются для государства непреодолимым препятствием для предоставления от- дельным российским производителям (в частности, судостроителям) неконкурентных преимуществ (преференций) для достижения тех или иных социально значимых целей.

3. Действующее законодательство не регулирует порядок принятия федеральным законодателем, Президентом и Правительством Российской Федерации решений, ограничивающих конкуренцию. И за принятием таких решений не осуществляется антимонопольный контроль.

4. Антимонопольное законодательство страны не предусматривает процедур и механизма компенсации убытков, возникающих в результате легального ограничения конкуренции в случаях, не подпадающих под установленные им антимонопольные запреты, что несет в себе потенциальную угрозу снижения качества инвестиционного климата и деловой активности (в том числе в сфере судостроения).

\section{Литература}

1. Огурцов А. П. Цель // Философский энциклопедический словарь / Гл. ред: Л. Ф. Ильичёв, П.Н. Федосеев, С. М. Ковалёв, В.Г. Панов. М.: Сов. энциклопедия, 1983. $840 \mathrm{c}$.

2. Taylor R. Action and purpose. N.Y.: Humanities Press, 1973. 269 p.

3. Панасенко Ю.А. Развитие конкурентоспособного потенциала отраслевой структуры промышленности. Дисс. ... канд. экон. наук. Краснодар, 2003. 169 с.

4. Максимов С.В. Семь аргументов в защиту научной специальности «конкурентное право» // Российское конкурентное право и экономика. 2017. № 4. С. 8.

\section{Сведения об авторе}

Башлаков-Николаев Игорь Васильевич: кандидат экономических наук, старший научный сотрудник Российского экономического университета им. Г.В. Плеханова, почетный работник антимонопольных органов России, член Научного совета РАН по проблемам защиты и развития конкуренции, член Ассоциации антимонопольных экспертов

Контактная информация:

Адрес: 117997, г. Москва, Стремянный пер., 36

E-mail:bniv@list.ru 